\title{
THE DYNAMICS OF GENETIC VARIABILITY IN THREE GENERATIONS OF MASS SELECTION FOR FAST GROWTH IN AFRICAN CATFISH, Clarias gariepinus ASSESSED BY MICROSATELLITE MARKERS
}

\author{
Imron, Bambang Iswanto, Huria Marnis, Rommy Suprapto, and Narita Syawalia Ridzwan \\ Research Institute for Fish Breeding
}

(Received 13 August 2015; Final revised 26 October 2015; Accepted 10 November 2015)

\begin{abstract}
Selective breeding aiming at improving the performance of economically important traits acts by exploiting population's phenotypic variance. Due to the relationship between phenotype and genotype, selection on phenotype may also affect the profile of genotype. This study was aimed to monitor the impact of three generations of mass selection for fast growth in African catfish, Clarias gariepinus, on genetic variability, assessed by microsatellite. A total of 350 fish representing four populations, namely a composite base population $(G-0)$, selected lines of the first generation $(G-1)$ to the third generation $(G-3)$, were sampled. The samples were screened for their genetic diversity using five microsatellite loci1 namely cga01, cga02, cga03, cga05, and cga09. Several genetic parameters including number of allele (A), allelic richness (AR), observed (Ho) and expected (He) heterozygosity, and fixation index (Fis) were evaluated. The results showed that there was a slight increase in the value of diversity indices in the G-1 relative to the $\mathrm{G}-0$ and to the other two generations. Among these parameters, the number of allele seemed to be the most sensitive parameter in detecting genetic changes. All populations experienced heterozygote deficit and positive fixation index indicating the phenomena of inbreeding. Overall, selection for growth for three generations in African catfish breeding program resulted in significant genetic differentiation between populations. Further, the level of genetic differentiation seemed to accumulate along with the number of generaton in breeding program. However, selection did not result in a decline in genetic diversity within population. A relatively short period of the program, along with the use a high number of broodstock (mating pairs) to produce each generation seems to be able to maintain the stability of genetic diversity of the population.
\end{abstract}

KEYWORDS: genetic changes, Clarias gariepinus, microsatellite, mass selection

\section{INTRODUCTION}

Catfish farming of the genus Clarias, specifically African catfish, Clarias gariepinus, has been one of important aquaculture business in Indonesia. Total production of this species reached 77,332 tons in 2006, and placed Indonesia as one of the major African catfish producing country in the world (FAO, 2009). Efforts to keep sustainability of the industry and to boost the production to a higher level have been carried out through several approaches: improvements in farming practices, feed and feeding strategy, and stocking genetically superior seed stocks. The supply of seed stocks that fulfil this quality are highly dependent on genetically-improved brood stocks produced by breeding programs. In fact, fish breeding

\# Correspondence: Research Institute for Fish Breeding. Jl. Raya 2 Sukamandi, Subang 41263, West Java, Indonesia. Phone: + (0260) 520500

E-mail: imronnawawi@gmail.com programs have played important roles in supporting the development of aquaculture industry of commercially important fishes such as the case with salmon, (Gjoen \& Bentsen, 1997), tilapia, Tilapia nilotica (Khaw et al., 2008), and white shrimp, Penaeus vannamei (Argue et al., 2002; Huang et al., 2012). A comprehensive review on the roles and prospects that fish breeding program can contribute to the development of aquaculture industry was provided by Nguyen (2015), Gjedrem \& Baranski (2009), Olesen et al. (2003), and Hulata (2001).

To support the development of African catfish farming in Indonesia, a breeding program aiming to improve growth performance was set up at the Research Institute for Fish Breeding (RIFB) in 2010. Following three generations of individual selection, the output of this program, a genetically improved strain of African catfish called Mutiara, accumulating some $40 \%$ selection response in growth trait, has been 
disseminated to the fish farmers since the end of 2014. To date, the program is continued and a sustainable genetic gain is expected to accumulate over generations. To achieve this objective, the breeding populations need to have sufficient genetic variations to allow them to continuously respond to selection. However, selectively bred populations, which in general have relatively small number of effective size, theoretically are prone to experience genetic changes (Serbezov et al., 2012). Empirical studies with Ayu, Plecoglasus altivelis (Ikeda et al., 2005) for instance, found that average number of allele and heterozygosity in hatchery populations were lower than their wildtype counterpart. Likewise, study in shrimp Fenneropenaeus chinensis (Li et al., 2006), suggested that genetic diversity tended to reduce, differentiation between generations became less, and the variation of genetic structure of the populations became smaller as the time of populations under selection increased. This information is important for breeding program as genetic variation of breeding populations may influence the capacity of the populations to respond to selection. Therefore, one of the main challenges faced by any breeding program is how to manage genetic variation, particularly those underlying the expression of phenotype of interest. Accordingly, it is important to monitor the distribution and magnitude of genetic variation in breeding population over generations.

To cope with the need to monitor the status of population's genetic variation, some breeders have implemented systems allowing them to check the status of their population's genetic variation. The systems have been the use of a variety of molecular genetic markers such as mitochondrial DNA, randomly amplified polymorphism DNA, and microsatellite DNA. The comprehensive review and description on various types of genetic markers, which are part of aquaculture genome technology can refer to Liu (2007). This system has been adopted for captive populations undergoing genetic improvement program for aquaculture (see e.g. Chen et al., 2008; Frost et al., 2006; Loukovitis et al., 2012) or for endangered populations kept for conservation purposes (Wasko et al., 2004).

This study was aimed to monitor the genetic changes in three generations of breeding populations of African catfish using microsatellite molecular markers. The changes would be examined by looking at the dynamics of genetic variation in both within and between populations. Specifically, it was emphasized on 1) identification whether genetic changes occurred; 2 ) if the changes occurred, what parameters of genetic variation best captured the changes, 3 ) the relationship between the magnitude of genetic changes and the time of population under selection, and 4) genetic structure of populations following three generations of selection.

\section{MATERIALS AND METHODS}

\section{Stocks}

The stocks consist of four populations representing different generation which were part of African catfish breeding program conducted at the Research Institute for Fish Breeding. They were a base population, which from now on is referred to as $\mathrm{G}-0$, and selected generations of the first to the third round of individual selection which was referred to as G-1 to $\mathrm{G}-3$, respectively. The base population was formed in 2011 (Table 1). It was a composite population established from full diallel crosses of 64 males and 50 females representing four strains of African catfish available in Indonesia as parental line. They were Dumbo, Paiton, Sangkuriang, and Egypt strains. Introduction history of the first three strains in Indonesia as well as their incorporation into breeding program at RIFB has been described (Imron et al., 2010) while that of the Egypt strain can be found in Iswanto et al. (2012).

The population of selection candidate of generation-1 $(\mathrm{G}-1)$ to generation-3 (G-3) were formed in 2012 to 2013 (Table 1). They were established from reciprocal mating among 50 males and 50 females. Eggs from 50 females were fertilized with a full mixture of sperm of 50 males. Each female was thus crossed with 50 males. The 50 different batches of eggs were then hatched and 1,000 larvae from each batch were grown separately for up to 25 days. After this, the batches were mixed for communal rearing. After approximately four weeks, the fry was graded into five size classes: $<3 \mathrm{~cm}, 3-5 \mathrm{~cm}, 5-7 \mathrm{~cm}, 7-9$ $\mathrm{cm}$, and $>9 \mathrm{~cm}$. The grading was carried out to minimize cannibalism. This respective group, which in a whole consists of approximately 30,000 fish, was then reared for two months in ponds with similar conditions. After two month of grow out, males and females were separated according to their sex, followed by selection of individuals based on predefined size criteria. Three percent of the best performing individuals (about $200 \mathrm{fish}$ ) within each gender were selected and tagged for a new selection round. Figure 1 shows schematic diagram of the breeding program implemented at the RIFB to establish the base population which was followed by recurrent individual selection aiming to improve growth trait.

\section{Sample Collection}

At the end of nursery period ( 60 day post hatched, $\mathrm{dph})$, fin clips were taken from individuals belonging 


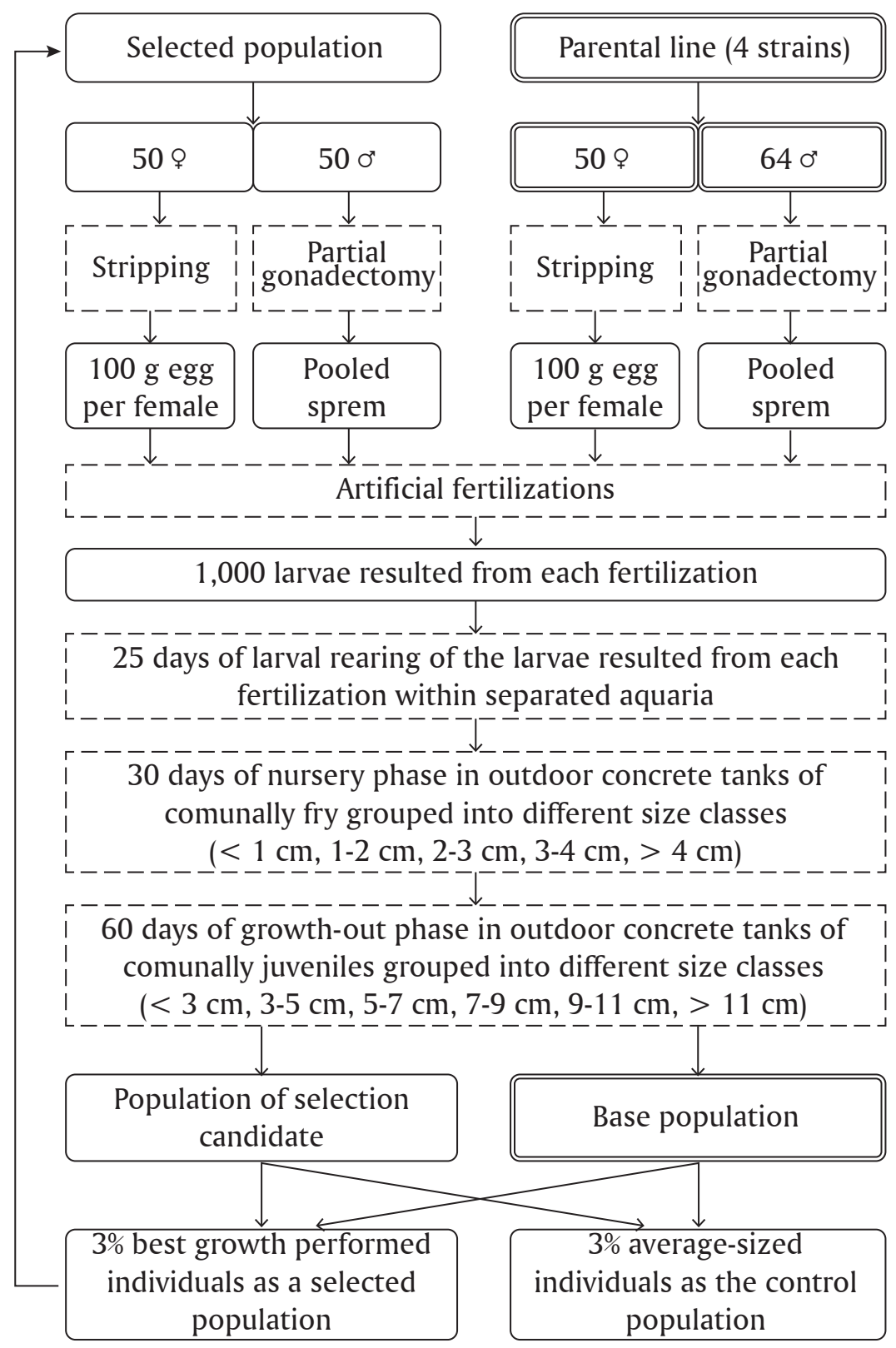

Figure 1. Schematic diagram of individual selection for fast growth in African catfish carried out at the RIFB. The double-solid line boxes indicate components' exclusively involved in the formation of the base population, while single solid and dotted line boxes indicate components and process associated with both base population and recurrent selection. The base population was synthesized from four strains: Egypt (E), Paiton (P), Sangkuriang (S), and Dumbo (D), with relative contribution was 16 for each male strain, and $16,14,12$, and 8 , respectively for each female strain

to each generations of selected stock. Non-destructive sampling was carried out by cutting approximately $3 \mathrm{~cm}$ end part of caudal fin of each individual sampled. Table 1 describes the date of sampling, number of individuals, and other attributes of the samples. Immediately after incision the individual tissue sample was then put in individual tubes filled with $80 \%$ ethanol and let them in room temperature until analyses.

\section{Microsatellite Analysis}

Microsatellite analysis consists of a series of steps including mainly genomic DNA exctraction, PCR amplification, and genotyping. Genomic DNA from each individual sample was extracted using the Gentra Puregene DNA Extraction Kit (QIAGEN) using a protocol provided by manufacturer. PCR amplification was carried on thermal profile MyCycler (Biorad), using five 
Table 1. Description of samples used in this study. The n, BW, TL, and dph denote number of sample, body weight, total length, and day post hatched, respectively

\begin{tabular}{ccccccl}
\hline \multirow{2}{*}{ Population } & \multirow{2}{*}{$\begin{array}{c}\text { Year of } \\
\text { collection }\end{array}$} & $\mathbf{n}$ & $\operatorname{Age}(\mathbf{d p h})$ & \multicolumn{2}{c}{ Size range } & \multirow{2}{*}{ Remarks } \\
\cline { 5 - 6 } & & & & $\mathbf{B W}(\mathbf{g})$ & TL $(\mathbf{c m})$ & \\
\hline G-0 & 2011 & 50 & 60 & $0.31-19.50$ & $1.40-13.30$ & Base population \\
G-1 & 2012 & 100 & 60 & $0.21-35.64$ & $1.50-16.65$ & Select first generation \\
G-2 & 2013 & 100 & 60 & $0.43-25.56$ & $3.20-15.70$ & Select second generation \\
G-3 & 2014 & 100 & 60 & $0.87-15.92$ & $5.20-13.60$ & Select third generation \\
\hline
\end{tabular}

primers set that were known to be polymorphic, namely cga-1, cga-2, cga-3, cga-5, and cga-9 (Galbusera et al., 1996) and a ready to use PCR master mix type it microsatellite (Qiagene). PCR products were then run for genotyping on a fragment analyzer system (QIAEXEL, Qiagene) allowing polymorphisms to be identified. A detailed description of this protocol has been described elsewhere (Imron et al., 2015).

\section{Data Analysis}

The dynamics of genetic variability of breeding populations as resulted from selection were analysed in several ways. The first, total genetic variation in four populations was partitioned into three components; within-individuals, among individuals within population, and between populations. This was intended to map the distribution and magnitude of genetic variation within those components. The partition was conducted using Analysis of molecular variance (AMOVA) (Schneider et al., 2000). The second, a number parameters describing genetic variability within and between populations were evaluated. They were number of detected allele (A), allelic richness (RS) namely standardized number of allele due to differences in sample size (El Mousadik \& Petit, 1996), observed (HO) and expected heterozygosities (HE), and fixation index within population (Fis). They were computed using statistical genetic software Arlequin (Schneider et al., 2000), Fstat version 2.9.3. (Goudet, 2001) and Genepop (Raymond \& Rousset, 1995). The magnitude of these parameters within populations was analyzed descriptively by looking at their trend in different generations. Additionally, pairwise comparisons to test for similarity in the mean of these parameters between populations were also carried out by implementing Welch's t-test, namely modified t-test due to unbalanced variance and sample size. Statistical significance of pairwise comparisons was adjusted using Bonferroni to correct for multiple comparisons.

The third, genetic differentiation among populations was evaluated using Fst parameter which was presented in pairwise comparison. Additionally, clustering of populations based on these Fst values was also displayed in phylogenetic tree. The tree was generated using the method of Unweighted Pair Group Method with Arithmetic Mean (UPGMA). Reliability of the tree was assessed using 1,000 times iteration of bootstrapping procedure. Both tree generation and reliability analysis were carried out using Poptree2, a software for constructing population tree from allele frequency data (Takezaki et al., 2010).

\section{RESULTS AND DISCUSSION}

\section{Distribution of Genetic Variation}

Partition of genetic variation into three hierarchical biological levels, namely within-individual, between individuals within population and between populations is presented in Table 2 . The table shows that majority of genetic variation occurred in within individuals and among individuals within populations, which together comprised 95\% of genetic variation. Genetic variation among populations contributed only $5 \%$ of the variation.

\section{Genetic Diversity Within the Respective Generations}

The profiles of several parameters of genetic diversity within population including number of allele (A), allelic richness (AR), observed ( $\mathrm{HO}$ ) and expected heterozygosity (HE) and fixation index (Fis) are presented in Figure 2, while statistical significance of each of these parameters in multiple comparisons among each others are presented in Table 3. The Figures show there was a slight increase in A, AR, Ho, and $\mathrm{He}$ in the $\mathrm{G}-1$ relative to its predecessor $(\mathrm{G}-0)$ or to its successive generations (G-2 and G-3). Meanwhile, the contrasting pattern was observed in the fixation index, in which its value in G-1 was the lowest.

Despite the emerging patterns, statistical significance test using pairwise comparisons (Table 4) shows that none of the values were statistically 
Table 2. Partition of genetic variation in four populations of African catfish breeding population coming from different generations into among-populations, among individuals within populations, and within individuals. The d.f. denotes degree of freedom

\begin{tabular}{lcccc}
\hline \multicolumn{1}{c}{ Source of variation } & d.f. & Sum of square & $\begin{array}{c}\text { Variance } \\
\text { components }\end{array}$ & $\begin{array}{c}\text { Percentage of } \\
\text { variation }\end{array}$ \\
\hline Among populations & 3 & 72.251 & 0.12221 & 5.41 \\
Among individuals within populations & 346 & $1,084.250$ & 0.99684 & 44.13 \\
Within individuals & 350 & 399.000 & 1.14000 & 50.46 \\
\hline \multicolumn{1}{c}{ Total } & $\mathbf{6 9 9}$ & $\mathbf{1 , 5 5 5 . 5 0 1}$ & $\mathbf{2 . 2 5 9 0 4}$ & \\
\hline
\end{tabular}
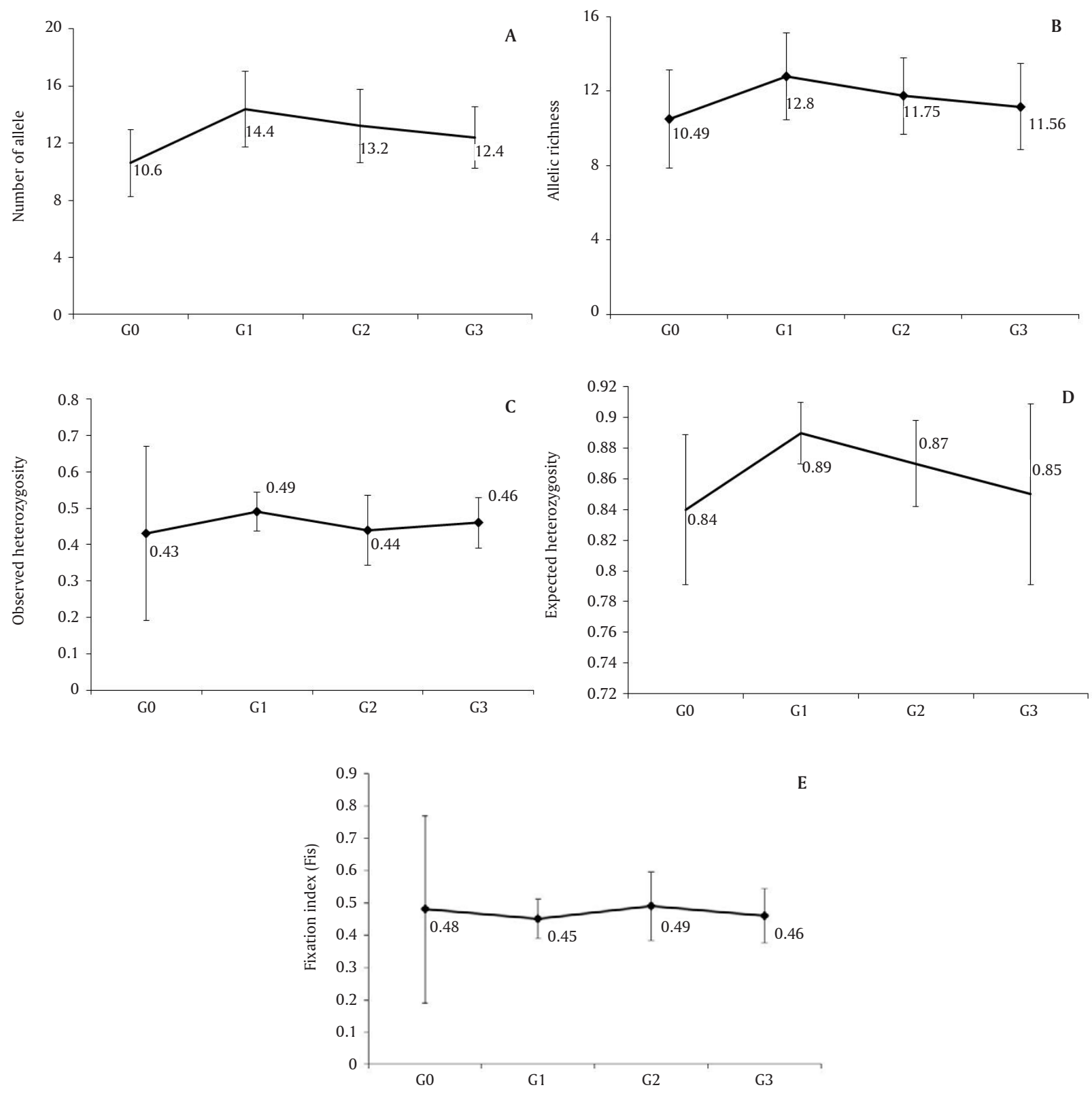

Figure 2. Trend of the mean ( \pm standard deviation) of several parameters of genetic diversity within populations in four populations of African catfish breeding program; G-0, G-1, G-2, and G-3 refer to the base population and selected generation-1 to generation-3, respectively 


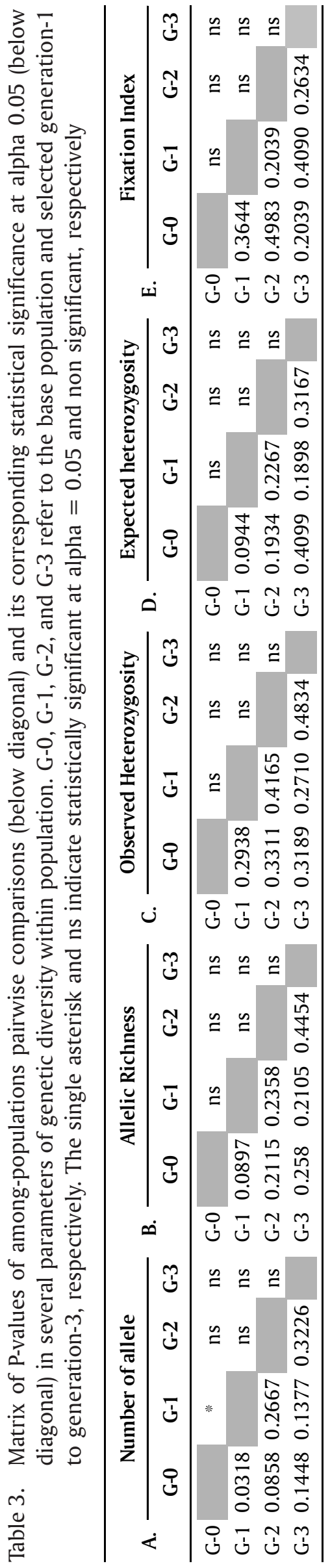


Table 4. Matrix of genetic differentiation among populations representing different generation, expressed in Fst (below diagonal) and its $\mathrm{P}$ value (above diagonal)

\begin{tabular}{ccccc}
\hline Population & G-0 & G-1 & G-2 & G-3 \\
\hline G-0 & - & 0.0000 & 0.0000 & 0.0000 \\
G-1 & 0.0725 & - & 0.0000 & 0.0000 \\
G-2 & 0.0875 & 0.0235 & - & 0.0000 \\
G-3 & 0.1054 & 0.0353 & 0.0541 & - \\
\hline
\end{tabular}

significant. The only parameter showing statistically significant difference was in the parameter of allelic number $(A)$ in which its value in $\mathrm{G}-1$ was higher than that in $\mathrm{G}-0$ and was statistically significant. However, following the implementation of Bonferroni correction for multiple pairwise comparisons (results not shown), the value was corrected and no longer statistically significant.

\section{Genetic Differentiation and Relationship Among Generations}

Genetic differentiation among generations, as expressed by Fst value averaged over five polymorphic loci is presented in Table 4. The table shows that breeding populations were not genetically homogenous. They formed genetically structured populations with genetic differentiation between all pair of populations ranged from 0.0235 to 0.1054 , and they were all statisticaly significant difference which were characterized by at least two distinctive features. Firstly, there was a linear and correlated pattern between the number of generation and the magnitude of genetic differentiation. The populations separated by a more distant time showed a higher genetic differentiation. The Fst values between G-0 and G-3 for instance, was higher than those of between G-0 and G-2 or between G-0 and G-1. Secondly, the most significant genetic differences, ranging from 0.0725 to 0.1054 was found between the base population against the rest. The magnitude of genetic differences among the pairs of selected generations (e.g. between G-1 and $\mathrm{G}-2$, or $\mathrm{G}-1$ and $\mathrm{G}-3$, and $\mathrm{G}-2$ and $\mathrm{G}-3$ ) were relatively smaller (Table 4 ). This pattern of differentiation was presented more distinctively in a dendrogram as shown in Figure 3.

The dendrogram built based on genetic distance shows that the populations could be divided into two clusters. The base population (G-0) formed a separate cluster while three successive selected generations $(\mathrm{G}-1-\mathrm{G}-3)$ formed a different cluster. The cumulative genetic distance built-up over two generations of selection (G-1-G-3) was comparable or even less than the genetic distance between the base population and the first generation of selection $(\mathrm{G}-\mathrm{O}-\mathrm{G}$ -
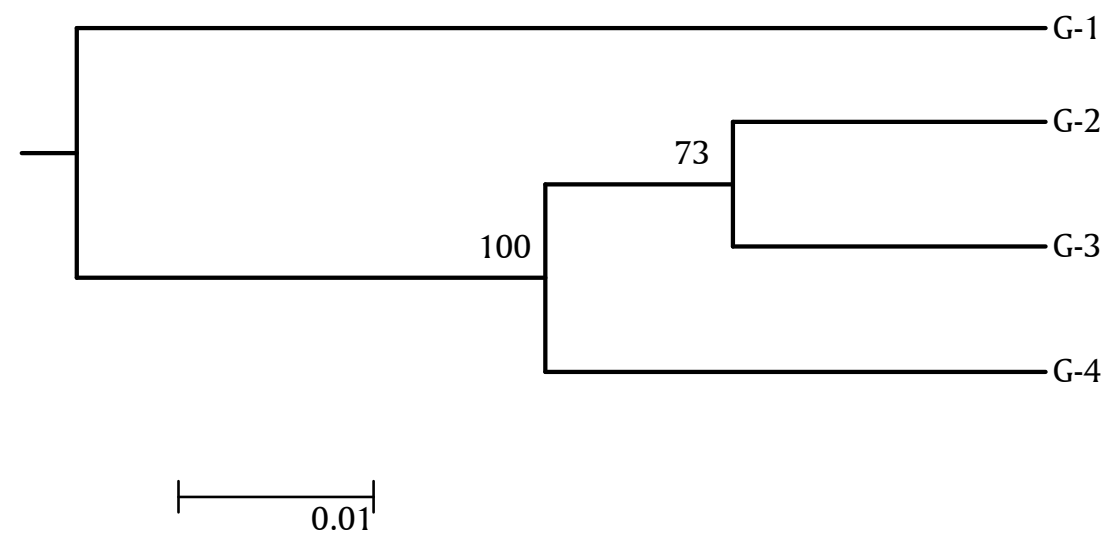

Figure 3. Dendrogram built based on genetic distance showing clustering of four breeding populations representing different generation of selection. The G-0, G-1, G-2, and G-3 indicate the base population and selected populations of generation1 , generation-2, and generation-3, respectively. Numbers above the branch indicate bootstrap value 
1). The selected populations are genetically more similar to each other than their similarity to the base population (Figure 3).

\section{Genetic Changes Within Population and Differentiation Between Populations}

Captive breeding over many generations would, in theory, reduce genetic variation, and increase inbreeding (Tave, 1999), as has been proven by several studies (see e.g. Iguchi et al., 1999; and RomanaEguia et al., 2005). Observation in breeding program of nile tilapia found that significant loss of genetic diversity has also been observed during the first selected generation to fourth selected generation. Moreover, the degree of inbreeding in selected lines were higher than that in control line (Romana-Eguia et al., 2005). Similar patterns were also observed in five consecutive breeding generations of mandarin fish Siniperca chuatsi (Basilewsky) (Yi et al., 2015).

The relatively stable genetic variability within population across different populations observed in this study appeared to be associated with breeding protocol adopted in this program and neutrality of the marker being used. The breeding protocols adopted have been intentionally designed to produce a sustainable genetic gain over many generations. A combination of such key components of breeding program as number of effective breeders $(\mathrm{Ne})$, balanced ratio of male and female, full diallel crossing in mating system, and high individual number of selection candidates, have led to the preserved genetic variability. The most convincing indicator showing that breeding populations have been well managed, could be looked at the fixation index (Fis). It is true that the sign of Fis value in all populations have been positive, meaning that populations had some level of inbreeding. However, for small and selectively bred populations, this situation is normal, as no such population can be free from inbreeding. The more important point is what profile they showed, specifically whether its values accumulated over generations. Level of inbreeding in captive population becomes a concern for breeders when it continuously accumulates over generations as it may affect biological performance of populations (Pekkala et al., 2014; Weigel, 2001). The data show that this was not the case with breeding populations of African catfish that currently being developed at the RIFB. Effective breeding number used in this program, namely a minimum 50 pairs could result in population with inbreeding rate $1 \%$ per generation (Bentsen \& Olesen, 2002). Following four cylces of breeding (including that at the base population), in theory, the last generation has accumulated $4 \%$ level of inbreeding. The fact that Fis were relatively stable meaning that either inbreeding level was not accumulated or the accumulation was too small to detect by microsatellite markers. In addition to the implementation of appropriate breeding protocol, unability to discover genetic changes within population might also associate with neutrality of the marker.

While artificial and directional selections were really implemented in the breeding population, no molecular signatures of these selection processes were detected. This is because the microsatellite molecular marker used in this study is generally accepted as neutral markers. Therefore, they might not preserve the signature left by selection process. This explained, in part, why allele frequency and other related withinpopulation genetic parameters were not significantly different among generations. Molecular signature of selection may be best captured by using selective or adaptive markers. Study in an endangered bird species for instance, found a stability in microsatellite diversity while reduction up $91 \%$ in diversity of immune system gene (Hartmann et al., 2014).

The phenomena shown in this study suggest that selective breeding did not reduce genetic variability because breeding strategies was able to keep inbreeding level from accumulating (Gjoen \& Bentsen, 1997). The lack of traceable changes in genetic diversity as result of selective breeding and the emerge of genetic structure observed in the present stydy was similar to that found in breeding program of Chinese shrimp, Penaeus chinensis. Following three generations of selection, the percentage of polymorphic loci and average gene diversity was not significantly different among generations. Conversely, AMOVA and pairwise Fst detected significant genetic differentiation among generations (Zhang et al., 2004).

There are four evolutionary forces that may shape the genetic structure of popualtions. They are migration, mutation, selection, and genetic drift (Hartl, 2001). The breeding populations are closed populations that migration as responsible force shaping the genetic structure can be omitted. Similarly, mutation is less likely to form the structure. Selection and genetic drift were the most likely evolutionary forces responsible for the observed genetic structure in the breeding population. Given the above mentioned arguments, genetic drift appeared to be the most plausible evolutionary force that has formed the genetic structure within the breeding populations. 


\section{Implications for breeding program}

The major challenge faced by any breeding program, including mass selection, is maintaining a balance of two interrelated but contrasting features, namely selection response and inbreeding level. The main goal of selective breeding program is obtaining a sustainable and long-term selection response or genetic gain. A high selection response normally is achieved by applying high selection intensity. However, implementing high selection intensity may put population at risk due to increased inbreeding coefficient that lead to inbreeding depression. Additionally, loss of genetic variation because of inbreeding was then found to reduce the response to selection (Bentsen \& Olesen, 2002). Therefore, keeping a balance in obtaining substantial selection response on one hand while keeping inbreeding coefficient remained low on the other is the main task that every breeder has to dealt with. The task is quite manageable for breeding program that allows breeders to identify the relatedness of their selected brood stocks, such as the case with within-family and between-family selections or combination of both. However, the task becomes complicated, if not impossible, for mass selection as no such information is available. In mass selection, selected brood stocks are simply drawn based on their performance. The drawback of this method is that there is possibility that the selected individuals are derived from restricted number of breeders. If this condition occurs, breeding population will accumulate higher inbreeding level, lose genetic diversity, and eventually reduce selection responses. The three generations of mass selection for fast growth in African catfish impelemented at RIFB, has not shown indications of declining in biological performance of breeding population. Selection candidate of generation-3 is still showing a high biological variation in growth trait and positive response to selection at $40 \%$ (Iswanto et al., 2014).

Based on the information gained in this study, it appears that breeding populations of African catfish at RIFB, up to the third generation, managed to maintain its genetic variability. These relatively stable genetic characteristics appeared to be associated with fulfilment of minimum effective breeding number $(\mathrm{Ne})$, mating system allowing maximum combination of gametes, and relatively small number of successive selections that have taken place in the breeding program. Selective breeding protocol currently adopted seemed to be able to keep the balance between gaining selective response on one hand while at the same time keeping low level of inbreeding on the other. This was supported by the fact that up to the third generation, $40 \%$ percent of selection response in growth trait has been accumulated (Iswanto et al., 2014). This information provides a good basis to continue the breeding program by implementing breeding protocol currently adopted. The key aspects of selective breeding currently adopted such as such as minimum effective breeding number of 100 , the balance ratio of male and female, full diallel crossing in mating and fertilization, and high number of selection candidates (30,000 fish), could be used as a base line protocol for selective breeding program implementing mass selection. Improvement to the protocol, for instance by incorporating minimum kinship when choosing broodstock to be mated (Hammerly et al., 2013; Willoughby et al., 2015), may improve further the performance of breeding program.

\section{CONCLUSION}

Three generations of mass selection for fast growth in African catfish, have changed genetic variability between population that resulted in a noticeable genetic structure, with the most significant sign was observed between the base and the selected populations. Genetic diversity within population, however, remained stable. No significant changes in genetic diversity parameters within populations were observed and thus selective breeding practices currently adopted is capable of maintaining genetic variation in breeding population.

\section{ACKNOWLEDGEMENT}

Authors would like to thank technical staff of African catfish Research Group and laboratory of Fish Physiology and Genetics for providing assistance during the course of the research. This Research was part of works on selective breeding for African catfish growth, funded by Ministry of Marine Affairs and Fisheries through the Agency for Marine and Fisheries Research and Development.

\section{REFERENCES}

Argue, B.J., Arce, S.M., Lotz, J.M., \& Moss, S.M. (2002). Selective breeding of Pacific white shrimp (Litopenaeus vannamei) for growth and resistance to Taura Syndrome Virus. Aquaculture, 204, 447460.

Bentsen, H.B., \& Olesen, I. (2002). Designing aquaculture mass selection programs to avoid high inbreeding rates. Aquaculture, 204, 349-359.

Chen, L., Li, Q., \& Yang, J. (2008). Microsatellite genetic variation in wild and hatchery populations of the sea cucumber (Apostichopus japonicus Selenka) from northern China. Aquaculture Research, 39, 1541-1549. 
El Mousadik, A., \& Petit, R. (1996). High level of genetic differentiation for allelic richness among populations of the argan tree Argania spinosa (L.) Skeels endemic to Morocco. Theoretical and Applied Genetics, 92, 832-839.

FAO. (2009). FishStat: Universal software for fishery statistical time series v. 2.3. Data and Statistics Unit. FAO, Rome.

Frost, L.A., Evans, B.S., \& Jerry, D.R. (2006). Loss of genetic diversity due to hatchery culture practices in barramundi (Lates calcarifer). Aquaculture, 261, 1056-1064.

Galbusera, P., Volckaert, F.A., Hellemans, B., \& Ollevier, F. (1996). Isolation and characterization of microsatellite markers in the African catfish Clarias gariepinus (Burchell, 1822). Molecular Ecology, 5, 703-705.

Gjedrem, T., \& Baranski, M. (2009). Selective breeding in aquaculture. An Introduction Springer, Dordrecht Heidelberg London New York.

Gjoen, H.M., \& Bentsen, H.B. (1997). Past, present, and future of genetic improvement in salmon aquaculture. ICES Journal of Marine Science, 54, 1009-1014.

Goudet, J. (2001). FSTAT, a program to estimate and test gene diversities and fixation indices (version 2.9.3). Available from http://www.unil.ch/izea/ softwares/fstat.html.

Hammerly, S.C., Morrow, M.E., \& Johnson, J.A. (2013). A comparison of pedigree-and DNA-based measures for identifying inbreeding depression in the critically endangered Attwater's Prairie-chicken. Molecular Ecology, 22, 5313-5328.

Hartl, D.L. (2001). A primer of population genetics. Sinauer Associates, Inc., Sunderland, MA.

Hartmann, S.A., Schaefer, H.M., \& Segelbacher, G. (2014). Genetic depletion at adaptive but not neutral loci in an endangered bird species. Molecular Ecology, 23, 5712-5725.

Huang, Y., Yin, Z., Weng, S., He, J., \& Li, S. (2012). Selective breeding and preliminary commercial performance of Penaeus vannamei for resistance to white spot syndrome virus (WSSV). Aquaculture, 364-365, 111-117.

Hulata, G. (2001). Genetic manipulations in aquaculture: a review of stock improvement by classical and modern technologies. Genetica, 111, 155-173.

Iguchi, K.i., Watanabe, K., \& Nishida, M. (1999). Reduced mitochondrial DNA variation in hatchery populations of ayu (Plecoglossus altivelis) cultured for multiple generations. Aquaculture, 178, 235243.

Ikeda, M., Takagi, S., \& Taniguchi, N. (2005). Relationships between genetic diversity and number of successive generations in hatchery populations of ayu Plecoglossus altivelis assessed by microsatellite DNA polymorphism. Nippon Suisan Gakkaishi (Japanese Edition), 71, 768-774.

Imron, Tahapari, E., Sari, R.D., \& Hudaidah, S. (2010). Growth and survival of catfish, Clarias Gariepinus, having different domestication history in indoor nursery. Proceedings of International Conference of Aquaculture Indonesia. Hang Tuah University, October 2010, p. 1109-1115.

Imron, Iswanto, B., Ridzwan, N.S., Suprapto, R., \& Marnis, H. (2015). Association of microsatellite genetic diversity with growth related traits in the base population of African catfish, breeding program. Indonesian Aquaculture Journal, 10(1), 1-11.

Iswanto, B., Marnis, H., Imron, \& Suprapto, R. (2014). Perakitan strain ikan lele tumbuh cepat melalui seleksi individu. Balai Penelitian Pemuliaan Ikan, Sukamandi.

Iswanto, B., Suprapto, R., Marnis, H., Ridzwan, N.S., \& Imron. (2012). Keragaan pertumbuhan larva ikan lele Mesir (Clarias gariepinus Burchell, 1822), p. 42-48, In Suwardjo et al., eds. Prosiding Seminar Nasional Perikanan Indonesia, Hasil Penelitian Perikanan dan Kelautan Tahun 2012. Pusat Penelitian dan Pengabdian Masyarakat, Sekolah Tinggi Perikanan, Badan Pengembangan Sumberdaya Manusia Kelautan dan Perikanan, Kementerian Kelautan dan Perikanan, Jakarta.

Khaw, H.L., Ponzoni, R.W., \& Danting, M.J.C. (2008). Estimation of genetic change in the GIFT strain of Nile tilapia (Oreochromis niloticus) by comparing contemporary progeny produced by males born in 1991 or in 2003. Aquaculture, 275, 64-69.

Li, Z., Li, J., Wang, Q., He, Y., \& Liu, P. (2006). The effects of selective breeding on the genetic structure of shrimp Fenneropenaeus chinensis populations. Aquaculture, 258, 278-282.

Liu, Z. (2007). Aquaculture genome technologies. Blackwell Publishing, Iowa, USA.

Loukovitis, D., Sarropoulou, E., Vogiatzi, E., Tsigenopoulos, C.S., Kotoulas, G., Magoulas, A., \& Chatziplis, D. (2012). Genetic variation in farmed populations of the gilthead sea bream Sparus aurata in Greece using microsatellite DNA markers. Aquaculture Research, 43, 239-246.

Nguyen, N.H. (2015). Genetic improvement for important farmed aquaculture species with a reference to carp, tilapia and prawns in Asia: achievements, lessons and challenges. Fish and Fisheries:n/a-n/a.

Olesen, I., Gjedrem, T., Bentsen, H.B., Gjerde, B., \& Rye, M. (2003). Breeding programs for sustainable aquaculture. Journal of Applied Aquaculture, 13, 179-204. 
Pekkala, N., Knott, K.E., Kotiaho, J.S., Nissinen, K., \& Puurtinen, M. (2014). The effect of inbreeding rate on fitness, inbreeding depression and heterosis over a range of inbreeding coefficients. Evolutionary Applications, 7, 1107-1119.

Raymond, M., \& Rousset, F. (1995). GENEPOP (version 1.2) population genetics software for exact test and ecumenism. Journal of Heredity, 86, 248249.

Romana-Eguia, M.R.R., Ikeda, M., Basiao, Z.U., \& Taniguchi, N. (2005). Genetic changes during mass selection for growth in Nile tilapia, Oreochromis niloticus (L.), assessed by microsatellites. Aquaculture Research, 36, 69-78.

Schneider, S., Roessli, D., \& Excoffier, L. (2000). Arlequin; A software for population genetic analysis data, 2.000 ed. Genetic and Biometry Laboratory, University of Geneva. Switzerland, $111 \mathrm{pp}$.

Serbezov, D., Jorde, P.E., Bernatchez, L., Olsen, E.M., \& llestad, L.A.r. VÃ. (2012). Short-term genetic changes: evaluating effective population size estimates in a comprehensively described brown trout (Salmo trutta) Population. Genetics, 191, 579592.

Takezaki, N., Nei, M., \& Tamura, K. (2010). POPTREE2: Software for Constructing population trees from allele frequency data and computing other population statistics with windows interface. Molecular Biology and Evolution, 27, 747-752.
Tave, D. (1999). Inbreeding and broodstock management. Fisheries technical paper No. 392, 392 ed. FAO. Rome, p. 122.

Wasko, A.P., Martins, C., Oliveira, C., Senhorini, J.A., \& Foresti, F. (2004). Genetic monitoring of the Amazonian fish matrincha? (Brycon cephalus) using RAPD markers: Insights into supportive breeding and conservation programmes. Journal of Applied Ichthyology, 20, 48-52.

Weigel, K.A. (2001). Controlling inbreeding in modern breeding programs. Journal of Dairy Science, 84, Supplement: E177-E184.

Willoughby, J.R., Fernandez, N.B., Lamb, M.C., Ivy, J.A., Lacy, R.C., \& DeWoody, J.A. (2015). The impacts of inbreeding, drift and selection on genetic diversity in captive breeding populations. Molecular Ecology, 24, 98-110.

Yi, T.L., Guo, W.J., Liang, X.F., Yang, M., Lv, L.Y., Tian, C.X., Song, Y., Zhao, C., \& Sun, J. (2015). Microsatellite analysis of genetic diversity and genetic structure in five consecutive breeding generations of mandarin fish Siniperca chuatsi (Basilewsky). Genetics and Molecular Research, 14, 2600-2607.

Zhang, L., Kong, X., Yu, Z., Kong, J., \& Chen, L. (2004). A survey of genetic changes and search for sexspecific markers by AFLP and SAMPL in a breeding program of Chinese shrimp (Penaeus chinensis). Journal of Shellfish Research, 23:897-901. 
